\title{
Changes in oxygenation and heart rate after administration of artificial surfactant (ALEC) to preterm infants
}

\author{
J S Ahluwalia, C J Morley
}

\begin{abstract}
To determine if changes in oxygenation and heart rate occur after surfactant, changes in these variables were recorded continuously for 15 minutes before, during, and 15 minutes after the administration of the artificial surfactant ALEC to 21 preterm infants ventilated for respiratory distress syndrome. Median (range) birth weight and gestation were 1199 (561-2680) $\mathrm{g}$ and 28 (21-43) weeks, respectively. The mean (SD) time taken for administration was $17.6(3.8)$ seconds. No clinically important changes resulted from the administration of ALEC in the mean (SD) values for oxygen saturation (before $91.3(3.4) \%$, during $90.7(3.2) \%$, after $90.4(3.7) \%$ ) and heart rate (before 143 (15), during 138 (17), after 142 (16)). The maximum change in mean arterial oxygen saturation $\left(\mathrm{SaO}_{2}\right)$ was a fall of $4 \cdot 8 \%$.

(Arch Dis Child 1995; 72: F121-F122)
\end{abstract}

Keywords: ALEC surfactant, oxygenation, heart rate, preterm infants.

Administration of exogenous surfactant to very premature infants with respiratory distress syndrome significantly reduces neonatal mortality. ${ }^{1}$ There are few data on the immediate effects of giving surfactant to these infants who have labile cardiorespiratory function and tolerate disconnection from the ventilator poorly. There are six preparations in common use, four of which - Exosurf, Survanta, Curosurf and ALEC - have a licence in the United Kingdom. The volumes and techniques of administration are all different. The volumes vary from $5 \mathrm{ml} / \mathrm{kg}$ to $1.2 \mathrm{ml} /$ dose. The administration techniques vary: slow instillation at the top of the endotracheal tube over a minimum of four minutes ${ }^{2}$; instillation via a catheter to the lower end of the endotracheal tube in four equal proportions with the infant in different positions ${ }^{3}$; a rapid bolus of a single dose via a catheter to the lower end of the endotracheal tube followed by hand ventilation with a resuscitation bag $^{4}$; and a single rapid bolus via a catheter to the lower end of the endotracheal tube. ${ }^{5}$

A report of the effect of different dosing techniques with Survanta showed that oxygen saturation and heart rate were reduced during the procedure, regardless of the technique used. ${ }^{3}$ Dorrepaal et al showed acute increases in cerebral blood flow and oxygenation during delivery of Curosurf, with no change in blood pressure. ${ }^{6}$ Halliday et al described an increase in oxygenation within 15 minutes of Curosurf administration but did not describe the effect on oxygenation during the administration. ${ }^{4}$ The Wellcome Foundation also reports a significant incidence of desaturation and bradycardias during dosing with Exosurf. ${ }^{2}$ Mendoza et al showed significant episodes of desaturation during the administration of both Exosurf and Survanta. ${ }^{7}$

\section{Methods}

This study was conducted in the Rosie Maternity Hospital, Cambridge, where ALEC was given routinely to babies of less than 30 weeks' gestation as soon as they were intubated after birth. Babies of older gestational ages were also treated with ALEC at intubation if they were at risk of developing respiratory distress syndrome because they were asphyxiated. A second dose was administered at about 1 hour of age if the infant was still intubated and a third dose was given at about 24 hours if the infant remained intubated and ventilated. Further doses were occasionally given to seriously ill infants.

ALEC was administered rapidly as a $1.2 \mathrm{ml}$ bolus through a fine catheter passed to the lower end of the endotracheal tube during a temporary period of disconnection from the ventilator. A rapid $2 \mathrm{ml}$ flush of air was then administered to ensure that no ALEC remained in the catheter.

Oxygen saturation $\left(\mathrm{SaO}_{2}\right)$, heart rate, intraarterial oxygen tension $\left(\mathrm{PaO}_{2}\right)$, if available, and airway pressure were recorded on to computer using a data acquisition program (CARDAS, Medical Scientific Ltd, Bedford). Data were recorded continuously for 15 minutes before, during the procedure, and for 15 minutes afterwards.

Ventilator settings and inspired oxygen concentration $\left(\mathrm{FIO}_{2}\right)$ remained unchanged throughout the period of recording. Because of the difficulty of physiological measurements during acute resuscitation in the delivery unit, these recordings were made on the neonatal unit usually at the time of the third dose of ALEC. Infants studied were selected on the basis of clinically requiring surfactant treatment at the time that recording equipment was available. There was no maximum ventilator pressure or $\mathrm{FIO}_{2}$ level above which infants were excluded from the study. 
Table 1 Demographic data

\begin{tabular}{lc}
\hline & Median (range) \\
\hline Gestation (weeks) & $28(25-37)$ \\
Birthweight (g) & $1199(561-2680)$ \\
Age at administration (hours) & $26(21-43)$ \\
Peak inspiratory pressure (cm $\left.\mathrm{H}_{2} \mathrm{O}\right)$ & $20(16-40)$ \\
Ventilator rate (per minute) & $65(10-90)$ \\
Fractional inspired oxygen & $0 \cdot 70(0 \cdot 30-0 \cdot 98)$ \\
\hline
\end{tabular}

Table 2 Oxygenation and heart rate before, during, and after the administration of $A L E C$ (values are mean (SD))

\begin{tabular}{|c|c|c|c|c|c|}
\hline & $\begin{array}{l}15 \text { minutes } \\
\text { before }\end{array}$ & $\begin{array}{l}\text { Difference } \\
\text { before-during }\end{array}$ & $\begin{array}{l}\text { During } \\
\text { administration }\end{array}$ & $\begin{array}{l}15 \text { minutes } \\
\text { afterwards }\end{array}$ & $\begin{array}{l}\text { Difference } \\
\text { before-after }\end{array}$ \\
\hline $\begin{array}{l}\text { Oxygen saturation \% } \\
(n=21)\end{array}$ & $91 \cdot 3(3.4)$ & $\stackrel{0.68}{(\text { SE } 0.41)}$ & $90 \cdot 7(3 \cdot 2)$ & $90.4(3.7)$ & $\begin{array}{l}0.90 \\
(\text { SE } 0.39)\end{array}$ \\
\hline $\begin{array}{l}\text { Heart rate per minute } \\
(\mathrm{n}=21)\end{array}$ & $143(15)$ & $\begin{array}{l}4 \cdot 72 \\
\quad(S E 2 \cdot 62)\end{array}$ & $138(17)$ & $142(16)$ & $\begin{array}{l}0.12 \\
\quad(S E 0.85)\end{array}$ \\
\hline $\begin{array}{l}\text { Intra-arterial oxygen } \\
\text { tension } \mathrm{kPa}(\mathrm{n}=12)\end{array}$ & $7.9(1.1)$ & $\begin{array}{l}0.37 \\
\quad(S E 0 \cdot 19)\end{array}$ & $7 \cdot 5(1 \cdot 3)$ & $7 \cdot 6(1.5)$ & $\begin{array}{l}0 \cdot 29 \\
\quad(S E 0 \cdot 23)\end{array}$ \\
\hline
\end{tabular}

\section{Results}

Twenty one infants were studied. Their demographic data are shown in table 1 . Although the intention was to keep the $\mathrm{FIO}_{2}$ unchanged throughout the period of recording, one infant desaturated acutely following surfactant administration and required a significant increase in $\mathrm{FiO}_{2}$ from $0 \cdot 40$ to $0 \cdot 80$. For the other 20 infants the $\mathrm{FIO}_{2}$ was unchanged.

The time taken to administer ALEC was determined from the recording of airway pressure as being the time the endotracheal tube was disconnected from the ventilator. The mean time taken to administer ALEC was $17 \cdot 6$ (SD 3.8) seconds with a minimum of 12 and a maximum of 26 seconds. The mean values for $\mathrm{SaO}_{2}$, heart rate, and $\mathrm{PaO}_{2}$ were calculated for each baby and for each time period. For the group as a whole, there were no clinically important differences in these parameters among the three time periods (table 2). Only the difference between the pre- and postadministration $\mathrm{SaO}_{2}$ reached significance $(\mathrm{p}=0 \cdot 03)$. The maximum change in the mean $\mathrm{SaO}_{2}$ for any baby, comparing the periods before and after surfactant administration, was a fall of $4 \cdot 8 \%$. A similar maximum fall of $4.7 \%$ was seen in the mean $\mathrm{SaO}_{2}$ comparing the periods before and during surfactant delivery. Accompanying maximum changes in heart rate for these periods were falls of 39 and 10 beats per minute, respectively. No infant had a mean heart rate below 99 beats per minute during any period.

\section{Discussion}

The changes in oxygenation and heart rate associated with the administration of ALEC compare favourably with the changes reported during the administration of Exosurf, ${ }^{2}$ where $22 \%$ of infants experienced a fall of at least $20 \%$ in oxygen saturation. In the study by Zola et al using Survanta, falls in $\mathrm{SaO}_{2}$ of around $10 \%$ were commonly seen, with accompanying falls in heart rate of the order of 40 beats per minute. ${ }^{3}$ Mendoza et al, looking at changes associated with the administration of Exosurf and Survanta, showed that infants spent nearly $25 \%$ of the time during dosing with an oxygen saturation of less than $85 \%$, regardless of which surfactant was used. ${ }^{7}$ Horbar $e t a l$, in a study comparing outcome using Exosurf and Survanta, noted oxygen saturations of less than $85 \%$ in $46 \%$ and $35 \%$ of infants, respectively, during administration of Exosurf and Survanta. ${ }^{8}$

The typical tidal volume for this group of infants in the acute stage of respiratory distress syndrome will be 6 to $8 \mathrm{ml} / \mathrm{kg}$ - that is, between 7 and $10 \mathrm{ml}$. The recommended volume of saline in which ALEC should be mixed for administration is $1.2 \mathrm{ml}$, representing $12-17 \%$ of the tidal volume for this group. This compares with volumes of up to $5 \mathrm{ml} / \mathrm{kg}$ for other surfactants, representing up to $85 \%$ of the tidal volume. The relatively small fall in oxygen saturation seen during ALEC administration may therefore be related to the small volume and consequently short disconnection time.

This study has shown that ALEC can be given rapidly to preterm infants with respiratory distress syndrome without clinically important changes in oxygenation or heart rate during or immediately after its administration.

JSA is funded by Wellbeing.

ALEC was donated by Britannia Pharmaceuticals Ltd, Redhill, Surrey, England.

1 Soll RF, McQueen MC. Respiratory distress syndrome. In: Sinclair JC, Bracken MB, eds. Effective care of the newborm. Oxford: Oxford University Press, 1992: 325-58.

2 Wellcome Burroughs Ltd. Product Monograph. Exosurf Neonatal, 9865. January 1991.

3 Zola EM, Gunkel JH, Chan RK, Lim MO, Knox I, Feldman $\mathrm{BH}$, et al. Comparison of three dosing procedures for administration of bovine surfactant to neonates with respiratory distress syndrome. $₹$ Pediatr 1993; 122: 453-9.

4 Halliday HL, McCord FB, McClure BG, Reid M. Acute effects of instillation of surfactant in severe respiratory distress syndrome. Arch Dis Child 1989; 64: 13-6.

5 Ten-centre trial of artificial surfactant (ALEC) in very premature babies. BMF 1987; 294: 991-6.

6 Dorrepaal CA, Benders MJNL, van de Bor P, van Bel F. Cerebral haemodynamics and oxygenation in preterm infants after low vs high dose surfactant replacement therapy. Biol Neonate 1993; 64: 193-200.

7 Mendoza E, McEvoy C, Nimnicht G, Durand $M$. Quantification of oxygen saturation during surfactant administration in infants with respiratory distress syndrome. Ped Res 1993; 33: 225A.

8 Horbar JD, Wright LL, Soll RF, Wright EC, Fancroft AA, Korores SB, et al. A multicentre randomized trial comparing two surfactants for the treatment of neonatal respiratory distress syndrome. $\mathcal{F}$ Pediatr 1993; 123: 757-66. 